\title{
THE PERFORMANCE EVALUATION OF INJECTOR USING
}

\author{
NUMERICAL TECHNIQUE \\ J. K. AJAY KUMAR ${ }^{1} \&$ SRINIVA. G $^{2 *}$ \\ ${ }^{I}$ Student, Department of Aeronautical \& Automobile Engineering, Manipal Institute of Technology,
} MAHE, Manipal, Karnataka, India

${ }^{2}$ Assistant Professor, Department of Aeronautical and Automobile Engineering, Manipal Institute of Technology, MAHE, Manipal, Karnataka, India

\begin{abstract}
In this study, the aeronautical and aerospace standard rocket injector have been analyzed with different aerodynamic parameters in order to understand the performance of the injectors in different atmospheric conditions. These injectors are the primary device to inject the fuel form the manifold to the ignition chamber. It creates the requited pressure, mass flow rate and the flow velocity in order to generate atomization of the fuel molecule. This atomization of the micro fuel droplet create fuel spray angle, which indeed produce high fuel burn rate. The injector with improper design may cause, unburnt fuel molecule, which will turn to carbon deposit inside the mixture chamber and gets corroded. In this paper the author has investigated the injector flow rate with respect to the injector throat area. The fuel used in this cold flow test study is commercial kerosene. The result indicates that, as the pressure at the inlet increases, the spray cone angle, mass flow rate and flow velocity also increases gradually. This numerical analysis where performed for various injector throat area with respect to various pressure rate from 20-100 psi. The best injector with all aerodynamic properties have been selected. This research paper will be benefit for the researchers and aeronautical industries, which help them to study the different aerodynamic parameter change in various injector throat area.
\end{abstract}

KEYWORDS: Rocket Engine, Spray Atomization, Fuel Injector, Aerodynamic Parameter \& Engine Nozzle

Received: May 18, 2018; Accepted: Jun 08, 2019; Published: Jul 15, 2019; Paper Id.: IJMPERDAUG201999

\section{INTRODUCTION}

Today in the model space era in the aerospace and aeronautical industries has developed with new technologies. Construction of a space standard rocket is huge and complicated in order to generate huge required thrust. The engine selected for these rockets are integrated with specialized fuel injector. These injectors provide the required mass flow to the ignition chamber with the designed fuel mixture rate. The fuel then reached to the injector section in order to generate the required atomization of the fuel. The important advantage of these injectors are, creates huge mass flow rate, especially in the application of turbine and rocket engines such as low pressure and good cone spray. Develops good mixture between air and fuel. The basic limitation of the liquid propellant engine is leakage, the high pressurized flow to the injector may cause in leakage problem.

Unburned air fuel mixture from the igniter which in turn develops the carbon deposition. This deposited carbon is always danger of any engine to operate in safe condition, this might become catastrophic failure. The gasoline-direct-injection compression ignition is the recent developed injector system for the liquid gasoline engine, which solve the major industrial leakage and increased fuel efficiency to 50 percent. And also increases the 
fuel burning time to reduce the unburnt fuel and the engine is hybrid with low cost. Nowadays injector with high accuracy sensor are inbuilt with the injector head, which controls the flow with the pilot valves. Technologies are developing as the need and the demand of the product increases.

\section{LITERATURE REVIEW}

Blast Atomization of the liquid fuel injection system which has been investigated with the experimental approach has been set for different pressure rate in order to finalize the injector spray angle. The atomizer injector is designed with different version of dimension with swirling motion. The parameter such as mass flow rate, pressure and the spray nozzle cone angle have been investigated in the experimental way. The injector performed with various cone angle from $0^{\circ}-35^{\circ}$ angle with pressure feed range from $20-100$ psi. With the help of particle image velocimeter the atomization and the droplets of the spray cone have been investigate. The author has concluded the spray droplet intensity increases as the mass flow rate increases and the orifice exit and the diameter of the injector ratio is zero [1].

Construction of electrical feed system for the liquid propellant engine with brass injector plate. Choosing of single plate injector element which is to be operated with different oxidizer and fuel mixture ratio. In this experimental test rig hydraulic oil is used as the injector fuel. The brass injector with five jet nozzle have been tested for the characteristic curves and relationships between the fuel hydraulic and the oxidizer. For the extremely light weigh injector with the five jet impingement, the mass flow rate has been increased to 20 percent and the fuel atomization has also increased [2].

By implementing the future additive manufacturing 3D printed engine injector for the liquid propulsion rocket engine and the application based on the rocket. With the miscellaneous usage of advanced CFD and Finite element Analysis the Inconel metal 3d printed injectors are been applied by the Airbus Safran Launch. The full scaled 3d printed design concept of the injectors has increased the level of structural strength such as tensile and the ultimate yield strength has been increased to 20 percent higher the comparing with the machined injectors. The result outcome of the Additive manufactured injector where, the author has compared the flow check result for coaxial swirl spray cone angle of both machined and additive manufactured. The subscale testing of the airbus Safran collaboration of the production of additive manufactured component are tested for non- destructive test. These technologies are being implemented to the Ariane 6 launcher [3].

The school of aeronautical and aerospace which is situated at the University of Purdue have designed a hybrid Rocket Design. This design and construction of a four nozzle rocket engine, which includes the hybrid injector and the separate injector plate design. The injector was in the operating condition for 550 psi. The water flow test has performed by the author for the cold flow test in order to calculate the injector sizing. It has been observed that pressure increases with increase in mass flow rate [4].

Recent advanced turbo pumped and gas pressurized injectors with highly complex automatic injection system are widely used in NASA, ESA and CNSA from china. The injector size and the atomization depends on the number of injection nozzles. The injection nozzles for the cold flow test are tested with the cold flow test, which is similar to falcon 9 upper stage engine. The injector is tested with the liquid oxygen and kerosene. During the test operation five main parameters to define the characteristics of the injector nozzle such as flame temperature, sizing, material heat and the specific heat transfer. The mathematical modelling of the injector which also includes the regenerative cooling. These property of cooling, reduces the internal temperature of the injector. This cooling technology protects the injectors form 
sudden failure due to thermal stress [5]. In the modern era of aviation the industries are in the research process of constructing the high speed engine with low noise and fuel requirement [6].

In order to get such high speed powered engine, the author had made a research and an experimental study on ultrasonic fuel injection system using a micro injector nozzle. Implantation of various diameter of the nozzle, the author has understand the atomization properties of the nozzle. The pressurization of this particular system was constructed with the gravity feed system. Seven cluster micro nozzles are constructed on the injector plate, in order to get the seven various parameter. Micro nozzle investigation resulted as the diameter of the nozzle increases the fuel droplet get narrow formation and the atomization of the fuel gets strong at the same time the mass flow rate of the flow also increases. The mean velocity of the droplet also increases with resected to the nozzle [7-8].

German students from the German aerospace center has developed the injection for the Helios hybrid rocket engine. The fast and efficient combustion of the injector for the atomization of the fuel with the small injector size of the droplet [9]. These small droplets mainly concentrates on the propellant mixing ratio, which also includes three nondimensional properties. The design values of the injector and the mass flow rate in the spray channel have been observed during the test, which resulted in the higher amount of orifice injection of the fluid and also the homogenous distribution of the atomized fuel [10].

\section{METHODOLOGY}

The design and the experimental analysis of the injector is taken for the reference from paper [1]. The numerical analysis of the 2D injector with the actual dimension has been designed with help of Ansys Geometry shown in figure 1

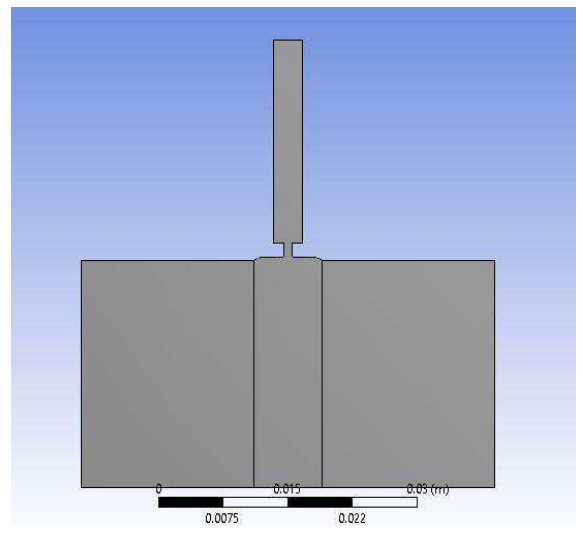

Figure 1

The 2D injector with inlet, outlet and the wall section are named as per the actual experimental setup. The meshing of the 2D injector and the injector plate are meshed with multi zone Quad/Tri Method shown in figure 2. The total nodes are 516034 and the elements are 514042 and the skewness ratio of the meshing is around 1.3e-010. Since the inlet fuel is kerosene for the cold flow numerical test, the properties of the kerosene are integrated to the boundary conditions. 


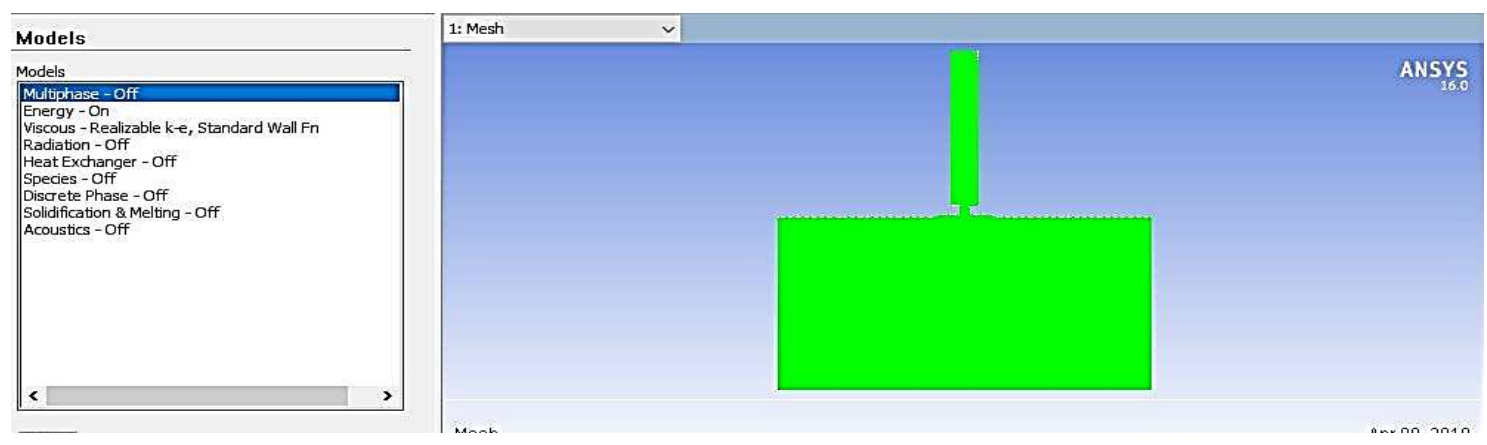

Figure 2

For the first boundary condition setup for the model, the solver used energy equation and for higher accuracy for the viscous model k-epsilon realizable has been used in the solver shown in figure 3 . And the boundary condition of the injector sections are tested with experimental data of pressure inlet from the range of 20 psi to 100 psi.

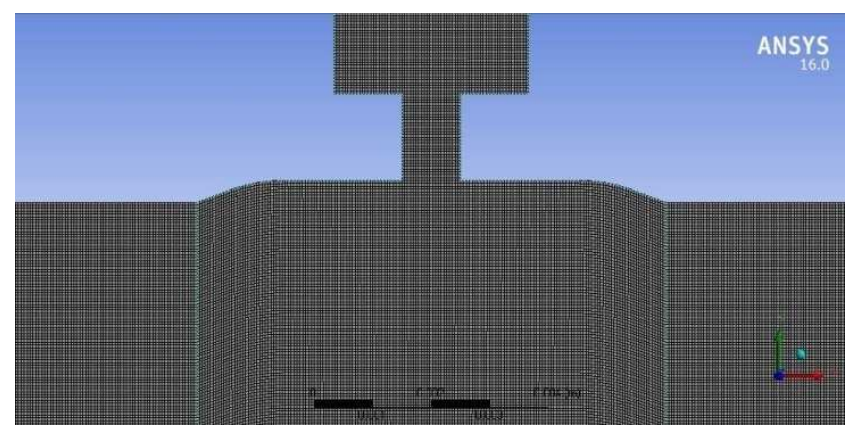

Figure 3

\section{RESULT AND DISCUSSIONS}

In this section, the experimental analysis which is already carried out by the author [1], is numerically inspected with the same boundary conditions. The major aerodynamic parameters are been inspected on the injector spray characteristics which also includes the nozzles size and the injector plate velocity distribution.

\section{Baseline Analysis Result}

In this baseline analysis, the comparison between the numerical and the experimental investigation of the injector mass flow output are been taken for finding the error approximation between the two various results with the same boundary conditions shown in table 1 .

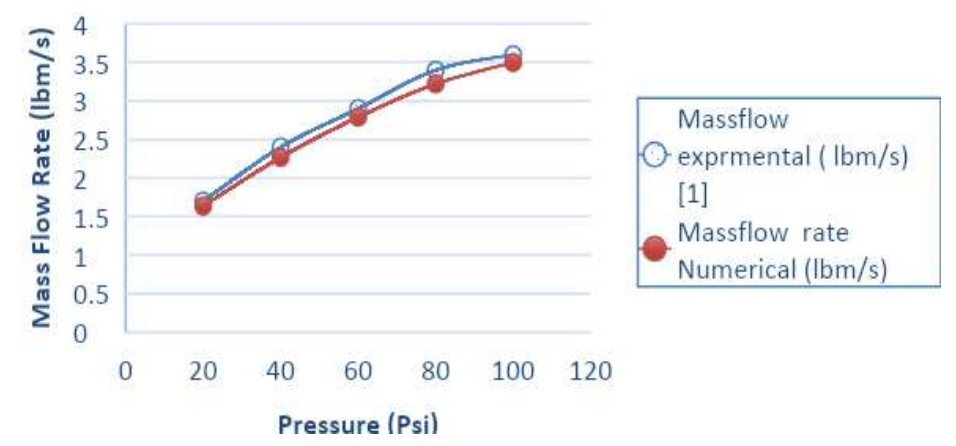

Graph 1: Validation of Experimental Data [1] 
The table explains the validation of the results for both experimental and numerical analysis of the injector graph 1.

Table 1: Validation of Exprimental and the Numerical Data [1]

\begin{tabular}{|c|c|c|c|c|}
\hline $\begin{array}{c}\text { Sl. } \\
\text { No }\end{array}$ & $\begin{array}{c}\text { Pressure } \\
(\text { Kpa) }\end{array}$ & $\begin{array}{c}\text { Experimental [1] } \\
\text { Mass Flow Rate (Kg/S) }\end{array}$ & $\begin{array}{c}\text { Numerical } \\
\text { Mass Flow Rate (Kg/S) }\end{array}$ & Error \% \\
\hline 1 & 137.8 & 0.77 & 0.73 & 3.8 \\
\hline 2 & 275.7 & 1.03 & 1.025 & 5.41 \\
\hline 3 & 413.6 & 1.32 & 1.26 & 3.8 \\
\hline 4 & 551.5 & 1.54 & 1.46 & 4.26 \\
\hline 5 & 689.4 & 1.63 & 1.58 & 2.83 \\
\hline
\end{tabular}

The validation of the experimental and the numerical of the injector states that the numerical analysis mass flow rate which nearly equal to the experimental mass flow rate shown in figure 5.

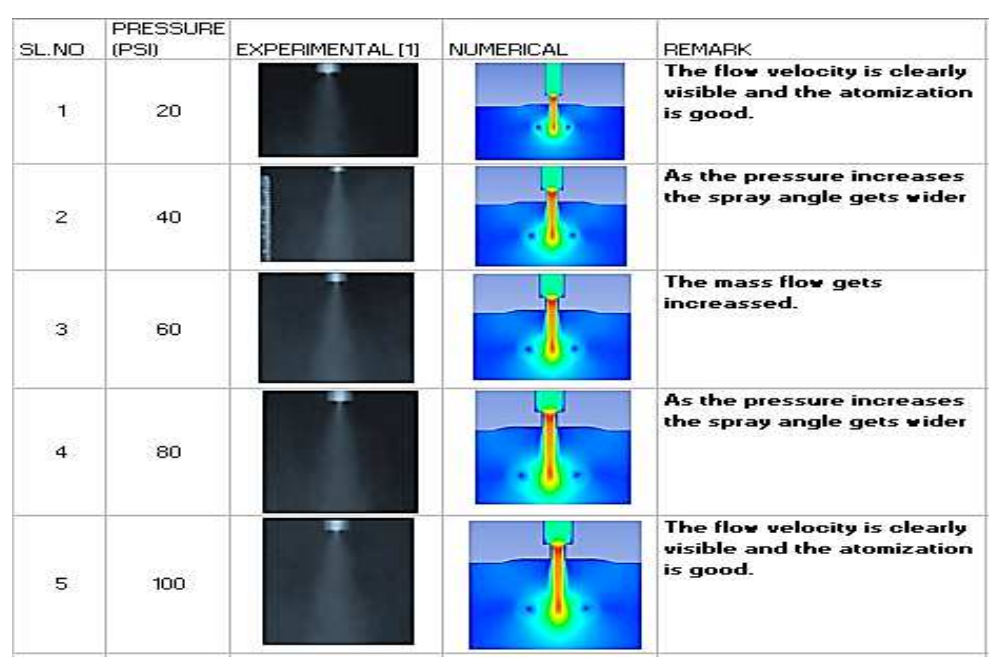

Figure 4

\section{Improved Result}

In this section, the mass flow rate, velocity and the spray atomization has been improved by changing the injector nozzle diameter form $1 \mathrm{~mm}$ dia to $1.04 \mathrm{~mm}$ dia.

\begin{tabular}{|c|c|c|c|c|c|}
\hline & & & \multicolumn{3}{|c|}{ NUMERICAL } \\
\hline SL.NO & PRESSURE & BEST INJECTOR & velocity & Pressure & Turbulence \\
\hline & & & & 4 & \\
\hline 2 & & & & & \\
\hline 3 & 60 & $1.04 \mathrm{~mm}$ & & 11 & \\
\hline 4 & 80 & $1.04 \mathrm{~mm}$ & & 11 & \\
\hline 5 & 100 & $1.04 \mathrm{~mm}$ & & 11 & \\
\hline
\end{tabular}

Figure 5

After various interation with various nozzle dia, $1.04 \mathrm{~mm}$ nozzle dia results better then other results shown 


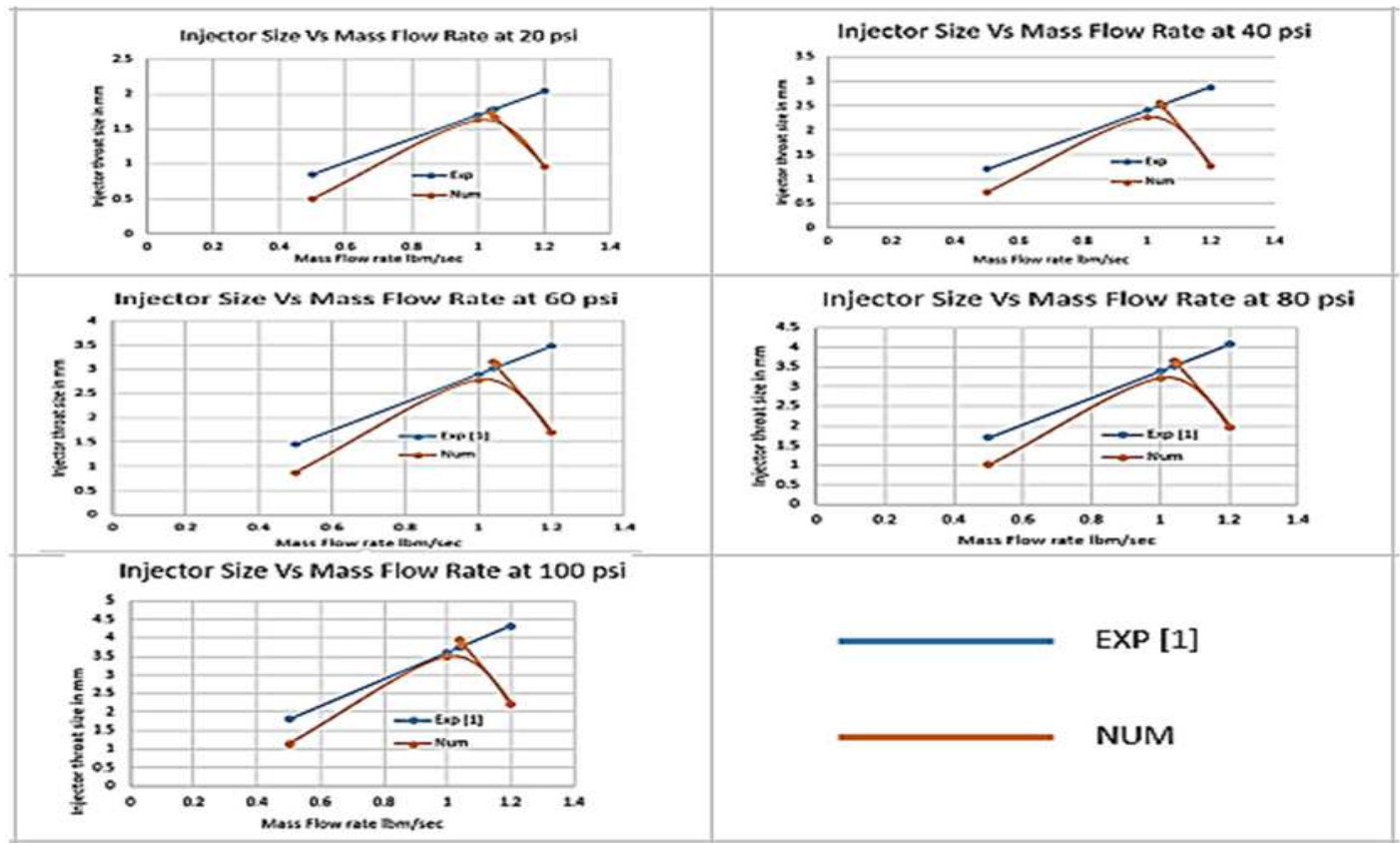

Figure 6: Improved Results at Nozzle dia $1.04 \mathrm{~mm}$

Improved Overall Results

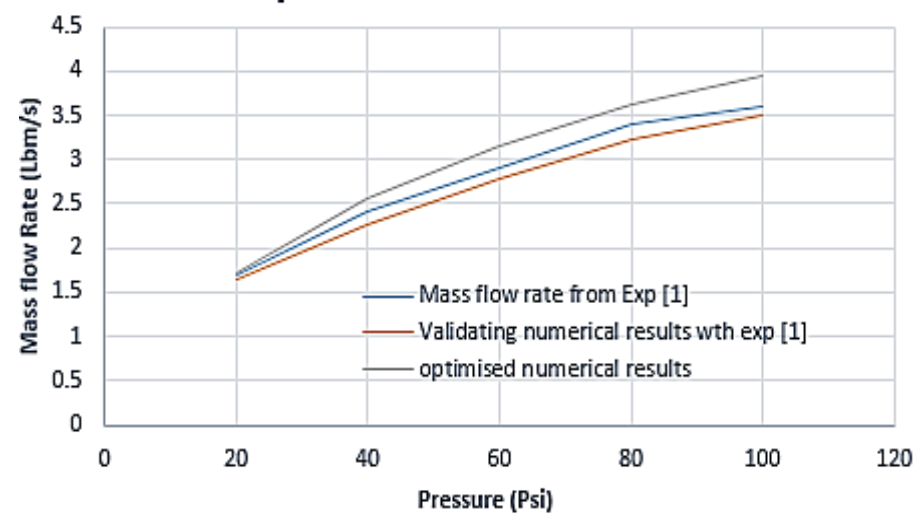

Figure 7: Experimental Vs Numerical for nozzle dia $1.04 \mathrm{~mm}$

\section{CONCLUSIONS}

- Numerical analysis of the injector plate with $1.04 \mathrm{~mm}$ throat diameter had done with the reference of the experimental investigation of injector plate with $1 \mathrm{~mm}$ throat diameter. The comparaison of the results are shown in figure 7 clearly states that the mass flow rate increases as the pressure increases.

- The injector performance resulted a perfect atomization at $1.04 \mathrm{~mm}$ nozzle diameter, where the pressure, velocity and the mass flow increases as comparing to experimental data.

- At $1.04 \mathrm{~mm}$ nozzle diameter the aerodynamical parameter values ranges about mach number - 0.04 , velocity - 16 $\mathrm{m} / \mathrm{s}$, mass flow rate $-0.80 \mathrm{~kg} / \mathrm{s}$ at $137 \mathrm{Kpa}$. As the pressure increases the parameter values also increases gradually. 


\section{REFERENCES}

1. H.M. Gad, I.A. Ibrahim (2018), "Experimental study of diesel fuel atomization performance of air blast atomizer", Experimental Thermal and Fluid Science 99 (2018) 211-218.

2. D. Spiller, (2013) "Design and Testing of a Demonstrator Electric-Pump Feed System for LiquidPropellant Rocket Engines”, Aerotecnica Missili \& Spazio, The Journal of Aerospace Science, Technology and Systems.

3. S. Soller*, R. Behr, (2017), "Design and Testing of Liquid Propellant Injectors for Additive Manufacturing”, 7th European Conference For Aerospace Sciences.

4. Eric Miklaszewski (2014) 'Hybrid Rocket Design/Build/Test Course at Purdue University', 49th AIAA/ASME/SAE/ASEE Joint Propulsion Conference

5. Mariana Peralta, (2016) Small liquid propellent rocket engine”,AIAA Publications

6. J.K Ajay Kumar, Srinivas G (2018) "Recent Trends in Theoretical, Experimental and Numerical techniques of Axial Flow Compressor in Aircraft Industry”, Journal of Advanced Research in Dynamical and Control Systems, Vol. 10, 03-Special Issue.

7. Mikiya ARAKI, (2006) “Ultrasonic Fuel Injector Using a Micro Nozzle Array”, ICLASS.

8. E.Gamper, (2013) "Design and test of oxide injectors for a hybrid rocket engine”, AIAA International Conference.

9. M. Thirupathi, (2015) “Design and Analysis of a Fuel Injector of a Liquid Rocket Engine”, (IJEAT).

10. Gang Zheng, (2014) "Numerical Simulation of the Atomization Process of a Like-doublet Impinging Rocket Injector" AsiaPacific International Symposium on Aerospace Technology. 
